\title{
A 60-year reconstructed high-resolution local meteorological data set in Central Sahel (1950-2009): evaluation, analysis and application to land surface modelling
}

Crystele Leauthaud (1,2), Bernard Cappelaere (1), Jérôme Demarty (1), Françoise Guichard (3), Cécile Velluet (1), Laurent Kergoat (4), Théo Vischel (5), Manuela Grippa (4), Mohammed Mouhaimouni (6), Ibrahim Bouzou Moussa (7), Ibrahim Mainassara (1,8), and Benjamin Sultan (9)

(1) HydroSciences Montpellier (HSM), CNRS, IRD, Université de Montpellier, Montpellier, France, (2) CIRAD, Montpellier, France (crystele.leauthaud@cirad.fr), (3) Centre National de Recherches Météorologiques (CNRM), UMR 3589, CNRS, Météo-France, Toulouse, France, (4) Géosciences Environnement Toulouse (GET), CNRS, IRD, Université de Toulouse, Toulouse, France, (5) Laboratoire des Transferts en Hydrologie et Environnement, UMR 5564, CNRS, IRD, Université Grenoble I, France, (6) Service Analyses Climatologiques, Direction de la Météorologie Nationale du Niger, Niamey, Niger, (7) Département de géographie, Université Abdou Moumouni, Niamey, Niger, (8) Représentation au Niger, IRD, Niamey, Niger, (9) Sorbonne Universités (UPMC Paris 6)-CNRS-IRD-MNHN, LOCEAN/IPSL, IRD, Paris, France

The Sahel has experienced strong climate variability in the past decades. Understanding its implications for natural and cultivated ecosystems is pivotal in a context of high population growth and mainly agriculture-based livelihoods. However, efforts to model processes at the land-atmosphere interface are hindered, particularly when the multi-decadal timescale is targeted, as climatic data are scarce, largely incomplete and often unreliable.

This study presents the generation of a long-term, high-temporal resolution, multivariate local climatic data set for Niamey, Central Sahel. The continuous series spans the period 1950-2009 at a 30-min timescale and includes ground station-based meteorological variables (precipitation, air temperature, relative and specific humidity, air pressure, wind speed, downwelling long- and short-wave radiation) as well as process-modelled surface fluxes (upwelling long- and short-wave radiation,latent, sensible and soil heat fluxes and surface temperature). A combination of complementary techniques (linear/spline regressions, a multivariate analogue method, artificial neural networks and recursive gap filling) was used to reconstruct missing meteorological data. The complete surface energy budget was then obtained for two dominant land cover types, fallow bush and millet, by applying the meteorological forcing data set to a finely field-calibrated land surface model. Uncertainty in reconstructed data was expressed by means of a stochastic ensemble of plausible historical time series. Climatological statistics were computed at sub-daily to decadal timescales and compared with local, regional and global data sets such as CRU and ERA-Interim. The reconstructed precipitation statistics, $\sim 1^{\circ} \mathrm{C}$ increase in mean annual temperature from 1950 to 2009, and mean diurnal and annual cycles for all variables were in good agreement with previous studies. The new data set, denoted NAD (Niamey Airport-derived set) and publicly available, can be used to investigate the water and energy cycles in Central Sahel, while the methodology can be applied to reconstruct series at other stations.

The study has been published in Int. J. Climatol. (2016), DOI: 10.1002/joc.4874 